\title{
НЕКОТОРЫЕ АСПЕКТЫ ПРЕПОДАВАНИЯ ФИЗИКИ В ТЕХНИЧЕСКОМ ВУЗЕ В ПЕРИОД ПАНДЕМИИ
}

\section{SOME ASPECTS OF TEACHING PHYSICS AT A TECHNICAL UNIVERSITY DURING THE PANDEMIC}

\section{T. Dubovitskaya \\ T. Turaeva \\ E. Belonogov}

Summary: The article is devoted to the generalization of the new experience of forced distance learning of students in a technical university, followed by substitution for blended learning, and highlights the questions of satisfaction with the educational process implemented during the coronavirus pandemic.

Keywords: distance learning, blended learning, laboratory practice, questionnaires.
Дубовицкая Татьяна Викторовна

К.n.н., дочент, ФГБОУ ВО «Воронежский государственный технический университет»

d.t.v.n.a@mail.ru

Тураева Татьяна Леонидовна

К.ф.-м.н, дочент, ФГБОУВО «Воронежский государственный технический университет» tlturaeva@mail.ru

Белоногов Евгений Константинович Д.ф.-м.н., профессор, ФГБОУВО «Воронежский государственный технический университет» ekbelonogov@mail.ru

Аннотация: Статья посвящена обобщению нового опыта вынужденного дистанционного обучения студентов в техническом вузе с последующим замещением на смешанное обучение и освещает вопросы удовлетворенности образовательным процессом, реализованным в период пандемии коронавируса в техническом вузе.

Ключевые слова: дистанционное обучение, смешанное обучение, лабораторный практикум, анкетирование.

спечения, интегрированных с целью сбора, обработки, хранения, распространения, отображения и использования информации. Смешанное обучение стремительно развивается благодаря использованию Интернет-технологий, современным методам коммуникации и обмена материалами и данными. Многие университеты внедряют смешанное обучение в учебный процесс, быстрыми темпами оно внедряется в сферу крупного бизнеса при организации корпоративного обучения.

Высшая школа в России пережила к началу второго семестра 2020-2021 учебного года уже два затяжных локдауна, в значительной степени обогнав по их длительности среднюю школу, что вынудило подавляющее большинство вузов перейти на дистанционное и смешанное обучение. В большинстве регионов сложилась такая эпидемиологическая ситуация, что большая часть вузов провела две промежуточные аттестации и одну итоговую удаленно. О смешанном и дистанционном обучении, как о формах образовательного процесса, через возможность доступа в Интернет с целью использования материалов видео- и телеконференций, электронной почты и онлайн общения написано и сказано было за последние двадцать лет очень много. Большинство авторов отмечали положительные аспекты, характеризующие дистанционное обучение, такие как пространственная и временная мобильность обучающего и обучаемого, непрерывная учебная работа обучаемого, непрерывное взаимодействие обучаемого и обучающе- 
го; специально подобранные учебные материалы с возможностью повторных просмотров и т.п. В тоже время, смешанное и дистанционное обучение характеризуется целым спектром не только педагогических, но психологических особенностей, которые по сравнению с традиционными формами обучения освещались недостаточHO.

Исследователи [6, 7] считают, что дистанционное обучение заменит традиционную систему инженерного образования, поскольку ускоряет процесс получения знаний. Однако, как показало наше исследование, участники образовательного процесса не готовы отказаться от личного очного общения и передачи знаний в учебных аудиториях, поскольку это развивает не только социальные и культурные навыки, но и крайне важно для формирования профессиональных компетенций будущих специалистов, особенно «наукоемких» направлений. Традиционное обучение отличается взаимодействием как между преподавателем и студентами, так и студентами между собой. Очное обучение позволяет делиться знаниями с другими, получать необходимую информацию, общаться и обмениваться опытом.

Психологические особенности дистанционного и смешанного обучения в вузах, в том числе вопрос эмоционального фактора восприятия учебного материала, стали предметом первого этапа нашего исследования посредством анкетирования, результаты которого мы приводим.

Анкетирование проводилось анонимно через Google Формы в Воронежском государственном техническом университете в рамках учебных курсов физики 2020 и 2021 гг. В работе приняли участие 323 студента направлений «Физическое материаловедение», «Металлургия» «Компьютерная безопасность» и «Радиотехника». Возраст участников составил от 18 до 22 лет, анкетируемые являлись студентами первого и второго года обучения.
Анкета содержала 18 вопросов, каждый из которых оценивался по шкале Ликерта со значением от -5 до +5 с нулевым показателем в центре. В анкетах фигурировал термин дистанционное обучение (ДО), который охватывал и аспект смешанного обучения с применением ИКТ.

Анкетируемым было предложено выразить степень позитивной/негативной оценки следующих утверждений.

1. дО - это когда не надо ездить в учебный корпус.

2. ДО развивает способность к самообразованию.

3. ДО учит организовывать свой учебный процесс (с учетом особенностей мышления): время, место учебы, скорость изучения.

4. ДО разнообразит дидактический материал (интернет-ресурс).

5. ДО повышает уровень ответственности (к себе, к учёбе).

6. ДО позволяет рационально распределять усилия.

7. Нет консультаций с преподавателем.

8. Нет возможности общения в коллективе, выступить устно перед аудиторией.

9. Невозможно освоить наиболее сложные темы самостоятельно.

10. Нет мотивации к самостоятельной работе, вследствие слабого контроля со стороны преподавателя.

11. Нет возможности сравнить результаты обучения (свои и других студентов).

12. Нет возможности выступать у доски, на семинаре, коллоквиуме.

13. Нет лектора, дающего материал с эмоциональной окраской.

14. Нет лекций и преподавателя у доски.

15. Нет лабораторных работ, выполняемых своими руками.

16. Есть возможность «несамостоятельной» работы (можно списать).

17. Сложно заставить себя учиться.

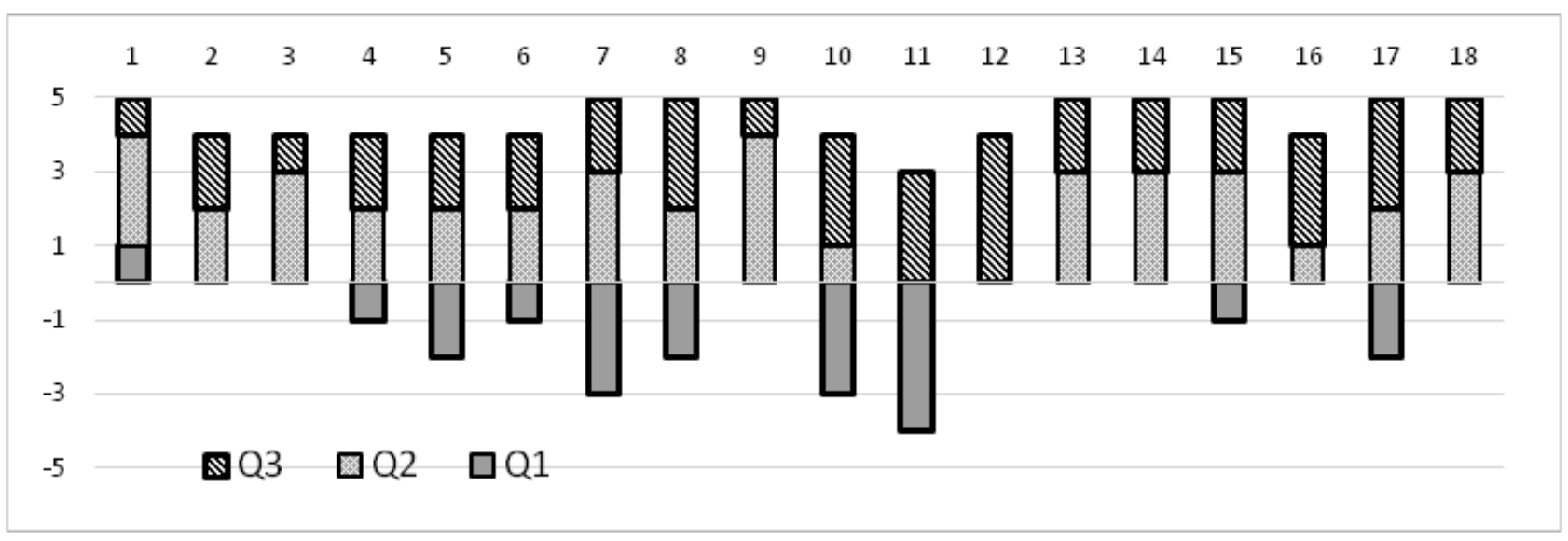

Рис. 1. Диаграмма размаха по результатам анкетирования студентов 
18. Нет особой учебной атмосферы, когда преподаватель и студент находятся «на одной волне» мысли.

19-я позиция в анкете предлагала высказать свои мысли по теме исследования в свободной форме.

Были получены следующие результаты, которые представлены на диаграмме размаха (рис. 1). На диаграмме отмечены три квартиля: Нижний квартиль (Q 1) это медиана нижней половины набора данных; Медиана (Q 2) - среднее значение набора данных; Верхний квартиль (Q 3) является медианным значением верхней половины набора данных. По горизонтали отмечены номера вопросов, по вертикали представлены значения по шкале Ликерта (Likert scale).

Из анализа данных видно, что подавляющее большинство опрашиваемых положительно оценивают обучение с применением дистанционных технологий (нижняя ось проградуирована от -5 до +5 с нулевым показателем в центре). Анализ анкет показал, что студенты выделяют для себя как «плюсы», так и «минусы». Чаще всего к «плюсам» студенты относили: возможность спокойно работать, не разрываясь между посещением пар и выполнением другой работы, самостоятельно определять режим дня и учиться в своем темпе

К «минусам» студенты отнесли: отсутствие четкого разделения на рабочее и нерабочее время; отсутствие живого общения с одногруппниками, чувство «покинутости», возникающее при необходимости оставаться один на один с большим объемом материалов, освоение которых должно происходить самостоятельно; необходимость постоянной самоорганизации и самоконтроля в процессе учебы.

Ряд вопросов анкеты (10, 11, 12, 16 и 17), связанные с мотивацией к обучению, самоконтролем и саморефлексией показали высокие негативные результаты. Верхний квартиль в отмеченных вопросах демонстрирует значительный процент ответивших на вопросы о недостаточной мотивации к обучению без внешнего контроля со стороны преподавателя, без возможности сравнить свои результаты с успехами других обучающихся. Из анализа свободных ответов следует, что большая часть обучаемых отрицательно реагировала на полное устра- нение преподавателя из учебного процесса в период дистанционного и смешанного обучения в пандемию, на формальный процесс обучения, ограниченную обратную связь от педагога или ее отсутствие.

Около половины обучающихся отметили, что в период дистанционного и смешанного обучения им не хватало практических навыков, которые могли быть получены лишь при выполнении лабораторных и практических работ в учебной аудитории (вопрос 15). Свободные ответы показали, что лишь немногих (около 15\% опрошенных) удовлетворила замена «натурных» работ на виртуальные. Около $15 \%$ анкетируемых отнеслись нейтрально к замене деятельности

Формально результаты диаграмм подтверждают слова из свободных ответов студентов: крайне важным студентам представляется не обезличенный процесс получения простой информации, а знаний, полученных в результате совместной работы между субъектами, преподаватель-студент, студент-студент.

Анкетируемые отмечали, что применение только дистанционных образовательных технологий в обучении приводит не только к социальным и личностным затруднениям, но и к невозможности полноценно освоить дисциплины, непосредственно связанные с будущими профессиями.

Подводя итоги, следует отметить, что формирование компетентности бакалавров и специалистов по направлениям подготовки «Физическое материаловедение», «Металлургия», «Компьютерная безопасность» и «Радиотехника» - это сложный процесс, который работает в рамках смешанного или дистанционного обучения, и позволяет студентам развиваться и улучшать свои учебные результаты лишь только при полной вовлеченности в процесс всех сторон учебного процесса в полном объеме независимо от формата обучения. Смешанное и дистанционное обучение позволяет формировать компетенции будущих специалистов под соответствующим руководством преподавателя, подобное обучение обеспечивает отличную интеллектуальную и высокотехничную среду, в которой возможно развитие необходимых навыков в современном информационном обществе.

\section{ЛИТЕРАТУРА}

1. Obukhova L.A., Galustyan O.V., Baklanov I.O., Belyaev R.V., Kolosova L.A., Dubovitskaya T.V. (2020) Formation of organizational competence of future engineers by means of blended learning. International Journal of Engineering Pedagogy, 10(2),119-127.

2. Белинская Е.П., Жичкина А.Е. Современные исследования виртуальной коммуникации: проблемы, гипотезы, результаты // Образование и информационная культура. М., 2000.

3. Киселев А.А. Дистанционное обучение студентов: проблемы и перспективы его развития после пандемии коронавируса // Развитие образования. - 
2020. - № 2 (8). - C. 97-100. D0I:10.31483/r-75354.

4. Geng, S., Law, K.M.Y., \& Niu, B. (2019). Investigating self-directed learning and technology readiness in blending learn-ing environment. International Journal of Educational Technology in Higher Education, 16(1)

5. Hui, Y.K., Li, C., Qian, S., \& Kwok, L.F. (2019). Learning engagement via promoting situational interest in a blended learning environment. Journal of Computing in Higher Education, 31(2), 408-425.

6. Ibrahim, M.M., \& Nat, M. (2019). Blended learning motivation model for instructors in higher education institutions. Inter-national Journal of Educational Technology in Higher Education, 16(1).

7. Wang, R. (2019). Massive open online course platform blended English teaching method based on model-view-controller framework. International Journal of Emerging Technologies in Learning, 14(16), 188-196.
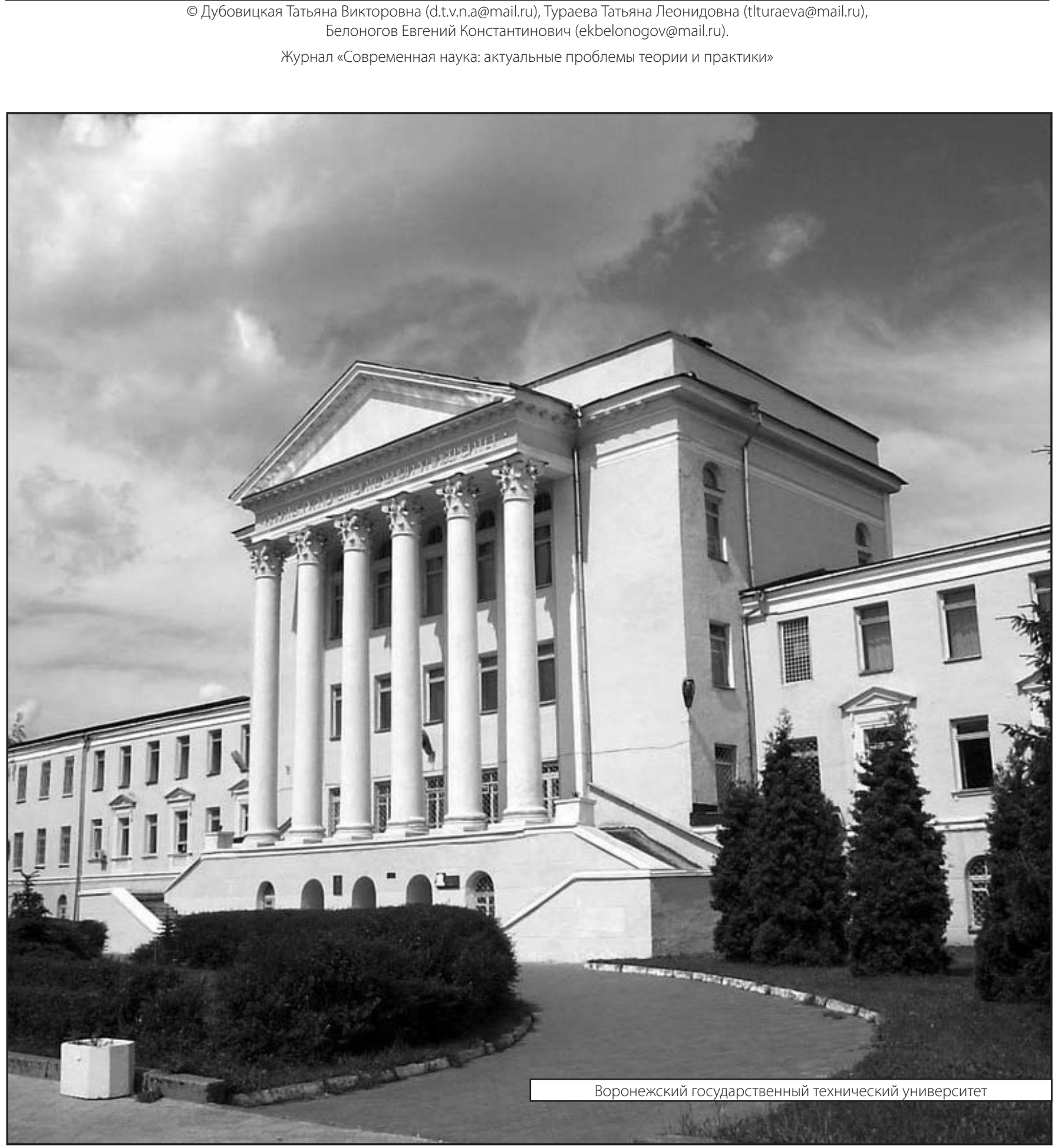